\title{
Clinical significance and predictive factors of early mas- sive recurrence after radiofrequency ablation in patients with a single small hepatocellular carcinoma
}

\author{
Ju-Yeon Cho ${ }^{1,2}$, Moon Seok Choi', Gil Sun Lee', Won Sohn ${ }^{1,3}$, Jemma Ahn', Dong-Hyun Sinn', Geum-Youn Gwak', \\ Yong-Han Paik', Joon Hyeok Lee', Kwang Cheol Koh', and Seung Woon Paik ${ }^{1}$ \\ 'Department of Medicine, Samsung Medical Center, Sungkyunkwan University School of Medicine, Seoul; ${ }^{2}$ Department of Medicine, \\ Chosun University School of Medicine, Gwangju; ${ }^{3}$ Department of Hepatology, Bundang Jesaeng Hospital, Seongnam, Korea
}

Background/Aims: Radiofrequency ablation (RFA) is one of the most frequently applied curative treatments in patients with a single small hepatocellular carcinoma (HCC). However, the clinical significance of and risk factors for early massive recurrence after RFA - a dreadful event limiting further curative treatment-have not been fully evaluated.

Methods: In total, 438 patients with a single HCC of size $\leq 3 \mathrm{~cm}$ who underwent percutaneous RFA as an initial treatment between 2006 and 2009 were included. Baseline patient characteristics, overall survival, predictive factors, and recurrence after RFA were evaluated. In addition, the incidence, impact on survival, and predictive factors of early massive recurrence, and initial recurrence beyond the Milan criteria within 2 years were also investigated.

Results: During the median follow-up of 68.4 months, recurrent HCC was confirmed in 302 (68.9\%) patients, with early massive recurrence in 27 patients (6.2\%). The 1-, 3-, and 5-year overall survival rates were 95.4\%, 84.7\%, and 81.8\%, respectively, in patients with no recurrence, $99.6 \%, 86.4 \%$, and $70.1 \%$ in patients with recurrence within the Milan criteria or late recurrence, and $92.6 \%, 46.5 \%$, and $0.05 \%$ in patients with early massive recurrence. Multivariable analysis identified older age, Child-Pugh score B or C, and early massive recurrence as predictive of poor overall survival. A tumor size of $\geq 2 \mathrm{~cm}$ and tumor location adjacent to the colon were independent risk factors predictive of early massive recurrence.

Conclusions: Early massive recurrence is independently predictive of poor overall survival after RFA in patients with a single small HCC. Tumors sized $\geq 2 \mathrm{~cm}$ and located adjacent to the colon appear to be independent risk factors for early massive recurrence. (Clin Mol Hepatol 2016;22:477-486)

Keywords: Hepatocellular carcinoma; Radiofrequency ablation; Milan criteria; Early recurrence

\section{INTRODUCTION}

Radiofrequency ablation (RFA) results in coagulation necrosis of the tumor exposed to heat generated by alternating electrical cur- rent (300-1,000 kHz) from the RF electrode tip.' The Barcelona Clinic Liver Cancer (BCLC) staging system and treatment strategy for hepatocellular carcinoma (HCC) endorsed by European Association for the Study of the Liver (EASL), American Association for

\section{Abbreviations:}

HCC, hepatocellular carcinoma; RFA, radiofrequency ablation

\section{Corresponding author : Moon Seok Choi}

Department of Medicine, Samsung Medical Center, Sungkyunkwan University School of Medicine, 81 Irwon-ro, Gangnam-gu, Seoul 06351, Korea

Tel: +82-2-3410-3409, Fax: +82-2-3410-6983

E-mail:drmschoi@gmail.com 
the Study of Liver Diseases (AASLD), and the Korean Liver Cancer Study Group (KLCGS)/National Cancer Center (NCC) recommend RFA as a curative treatment for patients with single or 3 tumors $<3 \mathrm{~cm}$ of diameter with ECOG 0 and Child-Pugh class A or B. ${ }^{2-4}$ RFA is also a treatment with curative intent when resection or liver transplantation is not feasible due to comorbidities of the patients. ${ }^{5}$ Overall 5 -year survival after RFA is reported to be 59.7 $60.2 \%$ paralleling those of hepatic resection. ${ }^{6,7}$

The recurrence of tumor after curative treatment is a significant risk to the overall prognosis of patients with HCC. Local tumor progression and intrahepatic distant recurrence after RFA at 5 years have been reported as $3.2-27.0 \%$ and $73.1 \%-74.8 \%$, respectively. ${ }^{6,7}$ Location and extents of recurrence after RFA are quite variable. Patients with recurrence of HCC after RFA can further undergo treatment with curative intent by administrating RFA, hepatic resection, or liver transplantation as long as they are eligible for the corresponding treatment. ${ }^{8-10}$ The Milan criteria (i.e., single $\mathrm{HCC}<5 \mathrm{~cm}$ or multiple HCCs $\leq 3$ in number and each $<3$ $\mathrm{cm}$ in diameter, no vascular invasion, and no extrahepatic metastasis) are being widely used as selection criteria for curative treatment in these settings. Unfortunately, recurrence of HCC beyond Milan criteria is not rare after RFA. ${ }^{11-15}$ Development of such recurrence limits treatment strategies to palliative approaches with less optimal prognosis. Furthermore, 'early' recurrence beyond Milan criteria can be a dreadful event for patents and physicians associated with poorer prognosis. ${ }^{16}$

The aim of this study was to determine clinical significance and predictive factors of early recurrence beyond Milan criteria, or early massive recurrence after RFA in patients with single small HCC.

\section{MATERIAL AND METHODS}

\section{Patients}

Between 2006 and 2009, 1,051 patients were newly diagnosed with single $\mathrm{HCC}$ within $3 \mathrm{~cm}$ in size and without vascular invasion or distant metastasis at Samsung Medical Center, Seoul, Korea. The diagnosis of HCC was established pathologically or clinically based on typical image findings with or without elevated serum AFP level in high risk groups according to the KLCGS/NCC guideline. ${ }^{4}$ Among these patients, 477 patients underwent percutaneous RFA as initial treatment modality. Inclusion criteria at our institution for RFA were as follows: (1) presence of a single nodular

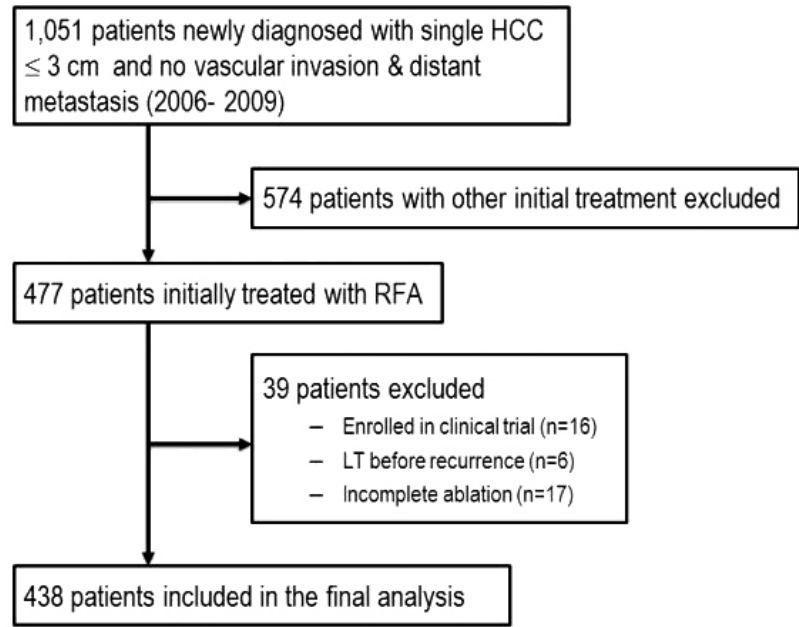

Figure 1. Flow chart of inclusion and exclusion criteria for the study. HCC, hepatocellular carcinoma; RFA, radiofrequency ablation.

$\mathrm{HCC} \leq 5 \mathrm{~cm}$ in maximum diameter or 3 or fewer HCCs with $\leq 3 \mathrm{~cm}$ in maximum diameter; (2) absence of vascular invasion or distant metastasis; (3) Child-Pugh class A or B; and (4) prothrombin time with an international normalized ratio $<1.7$ and platelet count $\geq 50,000$ cells $/ \mathrm{mm}^{3}$. In cases of a single HCC in a Child-Pugh class A patient without portal hypertension or hyperbilirubinemia, surgical resection was preferred. However, age, co-morbidity, and preference of the patients were also taken into account. The technical feasibility of RFA was assessed with planning ultrasonography exam by the radiologist who would perform the RFA procedure. ${ }^{6}$ Complete ablation was defined as presence of an ablation zone large enough to cover the entire index tumor on the CT scan taken immediately after the RFA. Thirty-nine patients were excluded due to enrollment in clinical study $(n=16)$, liver transplantation before recurrence $(n=6)$, or incomplete ablation $(n=17)$. Lastly, 438 patients with complete ablation were finally included in this study (Fig. 1).

\section{Procedure of RFA}

All RFA procedures were performed on an in-patient basis. RFA was approached percutaneously under ultrasound guidance (HDI 5000, Philips Healthcare, Best, The Netherlands; Acouson Sequoia 512, Siemens Medical Solutions, Mountain View, CA, USA; LOGIQ E9, GE Healthcare, Milwaukee, WI, USA). Patients were treated with $2 \%$ lidocaine hydrochloride at the puncture site and intravenous drip infusion of $50 \mathrm{mg}$ pethidine hydrochloride mixed with $50 \mathrm{ml}$ of $5 \%$ dextrose water. Cardiovascular and respiratory systems were continuously monitored during the procedure. Inter- 
nally cooled RF electrodes were used with a $200 \mathrm{~W}$ generator (VIVA RF System; STARmed, Goyang, Korea). The algorithm used for energy deposition followed the manufacturer's instructions for each RF electrode. Either a single straight electrode with an adjustable active tip (Proteus RF Electrode; STARmed, Goyang, Korea) or separable clustered electrodes (Octopus; STARmed, Goyang, Korea) were used according to the size and morphology of the tumors. Ablative margins of at least $5 \mathrm{~mm}$ beyond the margin of the tumors were planned for all tumors. Procedures were finished when the hyperechoic ablation zone on the ultrasonography was large enough to cover the entire tumor and the expected ablative margin. ${ }^{17}$

\section{Assessment}

Retrospective analysis of the baseline patient characteristics at

Table 1. Baseline characteristics of patients with a single small HCC treated with RFA

\begin{tabular}{|c|c|c|c|c|}
\hline & Total (438) & Recurrence (302) & No recurrence (136) & $P$-value \\
\hline $\operatorname{Age}^{*}$ & $57.1 \pm 9.5$ & $57.3 \pm 9.4$ & $56.6 \pm 9.8$ & 0.641 \\
\hline Sex & & & & 0.190 \\
\hline Male & $330(75.3)$ & $233(77.2)$ & $97(71.3)$ & \\
\hline Female & $108(24.7)$ & $69(22.8)$ & $39(28.7)$ & \\
\hline Etiology of liver diseases & & & & 0.504 \\
\hline HBV & $317(72.4)$ & $212(70.2)$ & $105(77.2)$ & \\
\hline $\mathrm{HCV}$ & $71(16.2)$ & $55(18.2)$ & $16(11.8)$ & \\
\hline Alcohol & $17(3.9)$ & $12(4.0)$ & $5(3.7)$ & \\
\hline HBV \& HCV & $5(1.1)$ & $3(1.0)$ & $2(1.5)$ & \\
\hline Others & $28(6.4)$ & $20(6.6)$ & $8(5.9)$ & \\
\hline Child-Pugh class & & & & 0.300 \\
\hline A & $376(85.9)$ & $263(87.1)$ & $113(83.1)$ & \\
\hline B & $62(14.1)$ & $39(12.9)$ & $23(16.9)$ & \\
\hline Alpha-fetoprotein ${ }^{*}(\mathrm{ng} / \mathrm{mL})$ & $139.7 \pm 431.0$ & $144.6 \pm 445.3$ & $128.9 \pm 398.9$ & 0.713 \\
\hline Tumor size $^{*}(\mathrm{~cm})$ & $1.85 \pm 0.55$ & $1.90 \pm 0.55$ & $1.75 \pm 0.55$ & 0.850 \\
\hline Conspicuity & & & & 0.599 \\
\hline Good & $355(81.1)$ & $247(81.8)$ & $108(79.4)$ & \\
\hline Poor & $83(18.9)$ & $55(18.2)$ & $28(20.6)$ & \\
\hline Tumor location & & & & 0.130 \\
\hline Adjacent to surface & $152(34.7)$ & $112(37.1)$ & $40(29.4)$ & \\
\hline Far from surface & $286(65.3)$ & $190(62.9)$ & $96(70.6)$ & \\
\hline Diaphragm & & & & 0.264 \\
\hline Adjacent & $36(8.2)$ & $28(9.3)$ & $8(5.9)$ & \\
\hline Not adjacent & $402(91.8)$ & $274(90.7)$ & $128(94.1)$ & \\
\hline Colon & & & & 0.205 \\
\hline Adjacent & $19(4.3)$ & $16(5.3)$ & $3(2.2)$ & \\
\hline Not adjacent & $419(95.7)$ & $286(94.7)$ & $133(97.8)$ & \\
\hline Vascular structures & & & & 0.525 \\
\hline Adjacent & $91(20.8)$ & $60(19.9)$ & $31(22.8)$ & \\
\hline Not adjacent & $347(79.2)$ & $242(80.1)$ & $105(77.2)$ & \\
\hline
\end{tabular}

HCC, hepatocellular carcinoma; RFA, radiofrequency ablation.

*Mean \pm SD 
diagnosis included age, sex, etiology of the liver disease, ChildPugh class, and alpha-fetoprotein (AFP) levels. The tumor size, conspicuity, and distance to the surface of the liver, diaphragm, colon, and vascular structures were also reviewed. The tumor within $1 \mathrm{~cm}$ of the liver surface, colon, diaphragm, or vascular structure was designated as being 'adjacent' or 'in proximity' to the corresponding structure. ${ }^{1}$

The patients were followed up regularly at 3 months interval for 2 years and at 6 months interval thereafter with dynamic CT or MRI for the assessment of recurrence. Local and remote recurrence, massive recurrence, and early massive recurrence were evaluated during follow up. While local recurrence was defined as the appearance of enhancing tumor around the ablation zone or resection margin, remote recurrence included the intrahepatic distant recurrence and extrahepatic recurrence. Further therapies such as RFA, resection, transarteiral chemoembolization, liver transplantation, and/or target therapy were applied for recurrent tumor according to the extent of recurrent tumors, liver function, and general performance of the patients.

Massive recurrence was defined as recurrence beyond Milan criteria, namely recurrence of HCC presenting as intrahepatic tumor(s) with size and/or numbers beyond Milan criteria, vascular invasion, or extrahepatic metastasis at the time of the first recurrence. Early massive recurrence was defined as initial recurrence of HCC beyond Milan criteria within 2 years after RFA. ${ }^{18}$ Incidence, clinical significance, and any predictive factors of early massive recurrence were evaluated. This study was approved by the institutional review board of our hospital.

\section{Statistical analysis}

Descriptive statistics were used to summarize baseline characteristics. The statistical results are presented as the mean \pm standard deviation (SD) or percentages. In all study subjects, continuous variables were compared parametrically using Student's $t$-test or non-parametrically using the Mann-Whitney $U$-test. Categorical variables were compared using the $\chi^{2}$-test or Fisher's exact test as appropriate. Cumulative rates of recurrence free survival were analyzed using the Kaplan-Meier method. Independent risk factors predicting early massive recurrence were analyzed using stepwise Cox regression analysis. A two-sided $P$ value $<0.05$ was taken as statistically significant. All statistical analyses were performed using SPSS version 19.0 (SPSS, Inc, an IBM Company, Chicago, IL, USA).

\section{RESULTS}

\section{Baseline characteristics of the patients}

The majority of the patients were male (75.3\%) with median age of 57 years (range: 30-82). The etiology of liver disease was associated with hepatitis B virus (HBV), hepatitis C virus (HCV), and combined HBV and HCV in 317 (72.4\%) patients, 71 (16.2\%) patients, and $5(1.1 \%)$ patients, respectively. Alcohol as an etiology of liver disease was noted in 17 (3.9\%) patients and cryptogenic liver disease was noted in $28(6.4 \%)$ patients. Child-Pugh class was A in $376(85.9 \%)$ and B or C in 62 (14.1\%) patients. The tumor size at initial presentation was $1.85 \pm 0.55 \mathrm{~cm}$ (mean $\pm S D$ ). Conspicuity of tumors was poor in $83(18.9 \%)$ patients. The tumor was adjacent to the surface, diaphragm, colon, and vascular structures in $152(34.7 \%), 36(8.2 \%), 19(4.3 \%)$, and 91 (20.8\%) patients, respectively. There was no significant difference of the patient and tumor characteristics in the recurrence and the nonrecurrence group (Table 1).

\section{Recurrence, massive recurrence, and early massive recurrence after RFA}

During median follow up period of 68.4 months (range: 1.0-

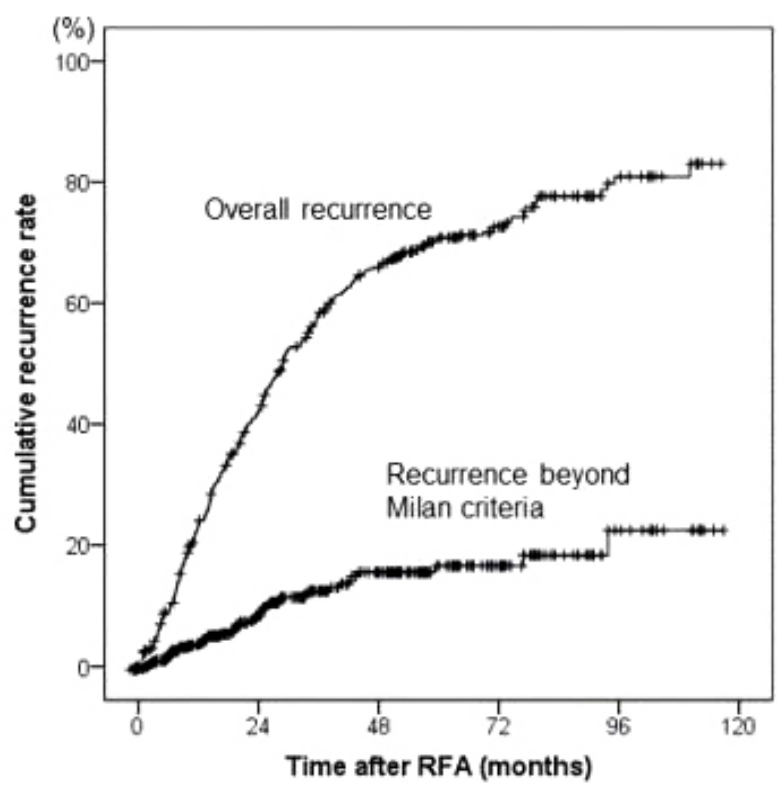

Figure 2. Overall recurrence and recurrence beyond the Milan criteria. The 1-, 3-, and 5-year cumulative overall recurrence rates were $23.1 \%, 58.4 \%$, and $70.8 \%$, respectively; the corresponding cumulative recurrence rates beyond the Milan criteria were $3.9 \%, 12.9 \%$, and $17.0 \%$. RFA, radiofrequency ablation. 

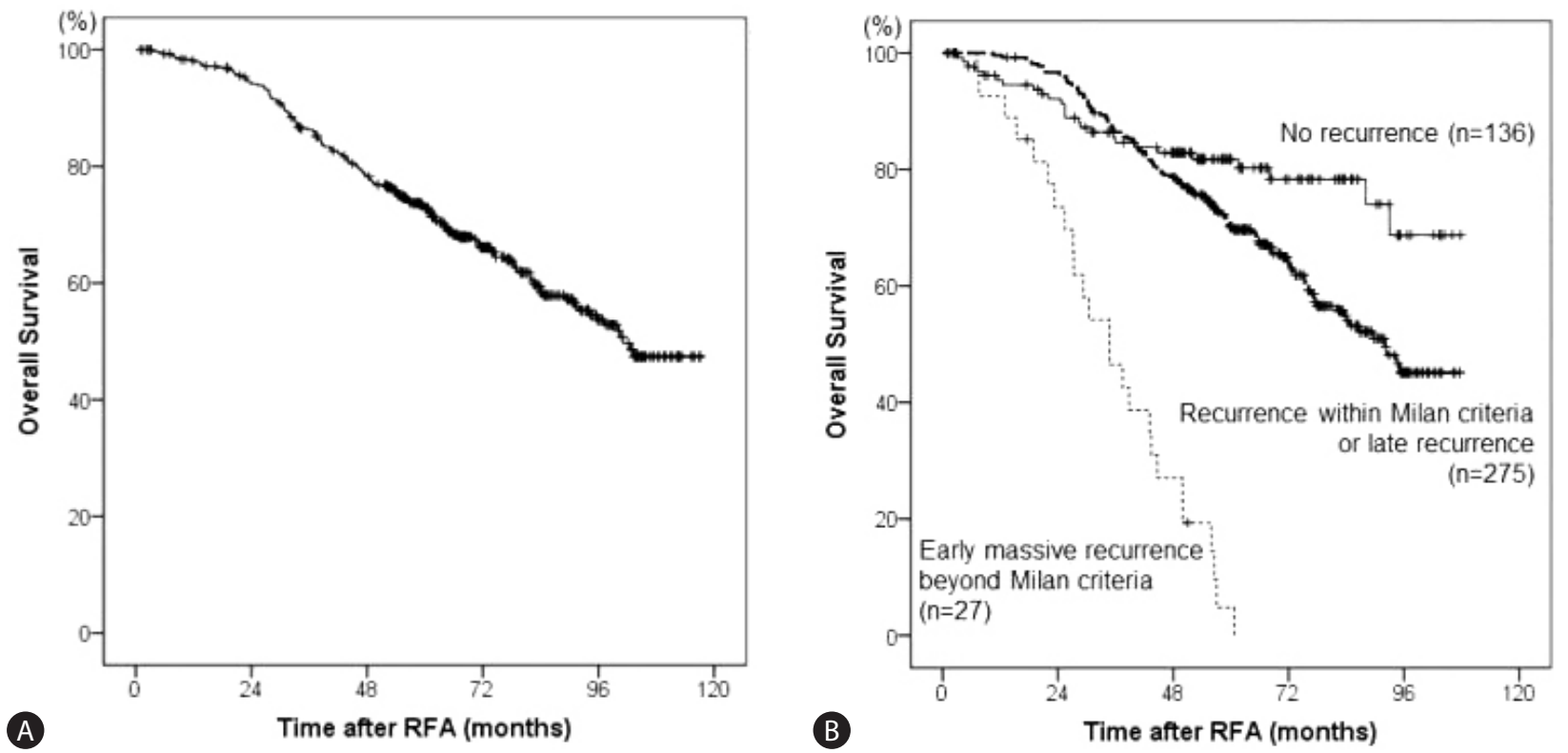

Figure 3. (A) Overall survival in the 438 patients. The 1-, 3-, and 5-year cumulative overall survival rates were $98.1 \%, 86.3 \%$, and $72.8 \%$, respectively. (B) Overall survival according to the pattern of recurrence. The 1-, 3-, and 5-year cumulative overall survival rates were $95.4 \%, 84.7 \%$, and $81.8 \%$, respectively, in patients with no recurrence $(n=136), 99.6 \%, 86.4 \%$, and $70.1 \%$ in patients with recurrence within the Milan criteria or late recurrence $(n=275)$, and $92.6 \%, 46.5 \%$, and $0.05 \%$ in patients with early massive recurrence $(n=27)(P<0.001)$. RFA, radiofrequency ablation.

Table 2. Predictive factors for overall survival after RFA of a single small HCC

\begin{tabular}{|c|c|c|c|c|}
\hline \multirow{2}{*}{ Factors } & \multicolumn{2}{|c|}{ Univariate } & \multicolumn{2}{|c|}{ Multivariate } \\
\hline & $95 \% \mathrm{Cl}$ & $P$-value & $95 \% \mathrm{Cl}$ & $P$-value \\
\hline Age & $1.03(1.01-1.05)$ & $<0.001$ & $1.04(1.02-1.05)$ & $<0.001$ \\
\hline \multicolumn{5}{|l|}{ Sex } \\
\hline Male & 1 & & & \\
\hline Female & $0.87(0.62-1.23)$ & 0.44 & & \\
\hline \multicolumn{5}{|l|}{ Initial size } \\
\hline$<2 \mathrm{~cm}$ & 1 & & & \\
\hline$\geq 2 \mathrm{~cm}$ & $1.15(0.85-1.56)$ & 0.37 & & \\
\hline $\operatorname{AFP}(\mathrm{ng} / \mathrm{mL})$ & $1.00(1.00-1.00)$ & & & \\
\hline Child Pugh class & & 0.65 & & \\
\hline A & 1 & & 1 & 0.03 \\
\hline $\mathrm{B}$ or $\mathrm{C}$ & $1.36(0.89-2.07)$ & 0.15 & $1.60(1.05-2.45)$ & \\
\hline \multicolumn{5}{|c|}{ Early massive recurrence } \\
\hline No & 1 & & 1 & $<0.001$ \\
\hline Yes & $6.99(4.48-10.93)$ & $<0.001$ & $8.43(5.34-13.30)$ & \\
\hline
\end{tabular}

HCC, hepatocellular carcinoma; RAF, radiofrequency ablation; AFP, alpha-fetoprotein.

117.1), recurrent HCC was confirmed in 302 (68.9\%) patients including 121 cases with local recurrence (27.6\%) and 181 cases $(41.3 \%)$ with remote recurrence. The 1-, 3-, and 5-year cumulative recurrence rates were $23.1 \%, 58.4 \%$, and $70.8 \%$, respectively. Massive recurrence was noted in 47 patients (10.7\%) (Fig. 2). Early massive recurrence was noted in 27 patients (6.2\%) as follows: detection of intrahepatic tumor(s) with size and/or numbers beyond Milan criteria $(n=11)$, vascular invasion $(n=3)$, and extrahepatic metastasis $(n=13)$. Subsequent treatments for patients with early massive recurrence were RFA $(n=10), \operatorname{TACE}(n=7)$, resection $(n=3)$, sorafenib $(n=2)$, and standard medical care $(n=5)$. 
Table 3. Predictive factors of early massive recurrence after RFA of a single small HCC

\begin{tabular}{|c|c|c|c|c|}
\hline \multirow{2}{*}{ Factors } & \multicolumn{2}{|c|}{ Univariable } & \multicolumn{2}{|c|}{ Multivariable } \\
\hline & $95 \% \mathrm{Cl}$ & $P$-value & $95 \% \mathrm{Cl}$ & $P$-value \\
\hline Age & $0.97(0.93-1.01)$ & 0.15 & & \\
\hline \multicolumn{5}{|l|}{ Sex } \\
\hline Male & 1 & & & \\
\hline Female & $0.89(0.36-2.21)$ & 0.81 & & \\
\hline \multicolumn{5}{|l|}{ Initial size } \\
\hline$<2 \mathrm{~cm}$ & 1 & & 1 & \\
\hline$\geq 2 \mathrm{~cm}$ & $2.67(1.20-5.94)$ & 0.02 & $2.30(1.02-5.16)$ & 0.04 \\
\hline $\operatorname{AFP}(\mathrm{ng} / \mathrm{mL})$ & $1.00(1.00-1.00)$ & 0.71 & & \\
\hline \multicolumn{5}{|c|}{ Child Pugh class } \\
\hline A & 1 & & & \\
\hline B or C & $0.52(0.12-2.18)$ & 0.37 & & \\
\hline \multicolumn{5}{|l|}{ Conspicuity } \\
\hline Good & 1 & & & \\
\hline $\mathrm{Bad}$ & $1.58(0.67-3.74)$ & 0.30 & & \\
\hline \multicolumn{5}{|c|}{ Adjacent to surface } \\
\hline No & 1 & & 1 & \\
\hline Yes & $2.43(1.14-5.19)$ & 0.02 & $1.76(0.78-3.96)$ & 0.17 \\
\hline \multicolumn{5}{|c|}{ Adjacent to diaphragm } \\
\hline No & 1 & & & \\
\hline Yes & $1.42(0.43-4.72)$ & 0.57 & & \\
\hline \multicolumn{5}{|c|}{ Adjacent to colon } \\
\hline No & 1 & & 1 & \\
\hline Yes & $7.05(2.84-17.51)$ & $<0.001$ & $4.64(1.75-12.31)$ & 0.002 \\
\hline \multicolumn{5}{|c|}{ Adjacent to vascular structure } \\
\hline No & 1 & & & \\
\hline Yes & $0.65(0.22-1.88)$ & 0.42 & & \\
\hline
\end{tabular}

RFA, radiofrequency ablation; HCC, hepatocellular carcinoma; AFP, alpha-fetoprotein.

\section{Overall survival after RFA and predictive factors}

The 1-, 3-, and 5-year cumulative rates of overall survival were $98.1 \%, 86.3 \%$, and $72.8 \%$, respectively (Fig. 3 A). Univariate analysis of predictive factors revealed age, Child-Pugh score, and early massive recurrence to be predictive of overall survival. Multivariate analysis identified older age $(\mathrm{OR}=1.04 ; 95 \% \mathrm{Cl} 1.02-1.05$; $P<0.001)$, Child-Pugh score B or C $(\mathrm{OR}=1.16 ; 95 \% \mathrm{Cl} 1.01-1.33$; $P=0.03)$, and early massive recurrence $(O R=8.07 ; 95 \% \mathrm{Cl} 5.13$ 16.27; $P<0.001)$ as the independent risk factors predictive of poor overall survival (Table 2). The 1-, 3-, and 5-year cumulative rates of overall survival were $95.4 \%, 84.7 \%$, and $81.8 \%$, respectively in patients with no recurrence $(n=136), 99.6 \%, 86.4 \%$, and
$70.1 \%$, respectively in patients with recurrence within Milan criteria or late recurrence, $(n=275), 92.6 \%, 46.5 \%$, and $0.05 \%$, respectively in patients with early massive recurrence $(n=27)$. Overall survival in patients with recurrence within Milan criteria or late recurrence was significantly better than those with early massive recurrence but significantly lower than those with no recurrence $(P<0.001)$ (Fig. 3B).

\section{Predictive factors for early massive recurrence after RFA}

Possible predictive factors for early massive recurrence were evaluated using Cox regression analysis. Age, sex (male vs. fe- 


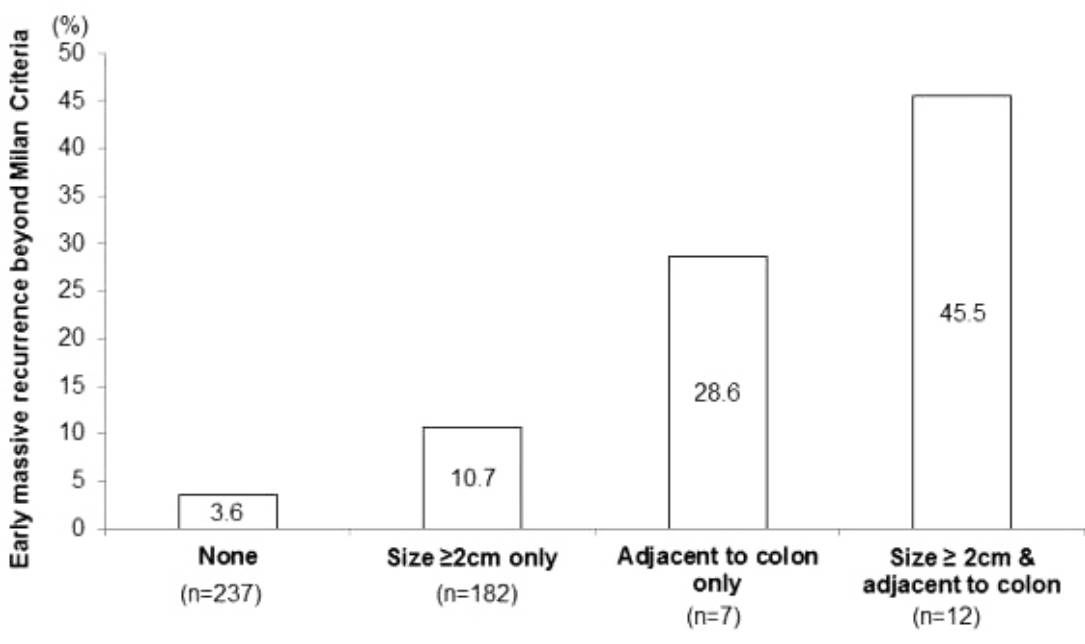

Figure 4. Early massive recurrence according to risk factors. Early massive recurrence was noted in $3.6 \%$ of patients with no risk factors $(n=237)$, $10.7 \%$ in those with a tumor sized $\geq 2 \mathrm{~cm}$ and not adjacent to the colon ( $n=182), 28.6 \%$ in those with tumors adjacent to the colon and sized $<2 \mathrm{~cm}(\mathrm{n}=7)$, and $45.5 \%$ in tumors sized $\geq 2 \mathrm{~cm}$ and adjacent to the colon $(n=12)(P<0.001)$. male), initial tumor size $(<2 \mathrm{~cm}$ vs. $\geq 2 \mathrm{~cm})$, AFP, Child-Pugh class (A vs $B$ or $C$ ), tumor location (not adjacent to surface vs. adjacent to surface), conspicuity (good vs. bad), diaphragm (not adjacent vs. adjacent), colon (not adjacent vs. adjacent), and vascular structures (not adjacent vs. adjacent) were included in the univariate analysis. Among them, 3 factors including initial tumor size $\geq$ $2 \mathrm{~cm}$, tumor near the surface, and tumor adjacent to the colon were associated with early massive recurrence by univariate analysis. Initial tumor size $\geq 2 \mathrm{~cm}(\mathrm{OR}=2.30 ; 95 \% \mathrm{Cl} 1.02-5.16 ; P=0.04)$ and tumor adjacent to the colon $(\mathrm{OR}=4.64 ; 95 \% \mathrm{Cl} 1.75-12.31$; $P=0.002$ ) were identified as independent risk factors predictive of early massive recurrence by multivariate analysis (Table 3 ).

Probability of early massive recurrence was assessed according to risk factors. Early massive recurrence was noted in $3.6 \%$ in patients with no risk factors $(n=237), 10.7 \%$ in those with tumor size $\geq 2 \mathrm{~cm}$ only ( $n=182), 28.6 \%$ in those with tumor adjacent coIon only $(n=7)$, and $45.5 \%$ in tumor size $\geq 2 \mathrm{~cm}$ and adjacent to colon $(n=12)(P<0.001)$ (Fig. 4).

\section{DISCUSSION}

RFA is one of the most commonly applied curative treatment modalities in patients with single small HCC showing clinical outcomes comparable to that of surgical resection. However, clinical significance and risk factors of early massive recurrence after RFA has not been fully evaluated. During median follow up of 68.4 months (range: 1.0-117.1) in 438 patients with single $\leq 3 \mathrm{~cm} \mathrm{HCC}$ successfully treated with RFA in this study, the 1-, 3-, and 5-year initial massive recurrence rates were $3.9 \%, 12.9 \%$, and $17 \%$, re- spectively. Early massive recurrence, noted in 27 patients (6.2\%), was identified as an independent predictor of poor survival and associated with tumor size $\geq 2 \mathrm{~cm}$ and proximity to colon.

Although recurrence after RFA is a common problem, favorable outcome in patients with recurrence can be expected as long as curative treatment is applicable. A recent study by Chan, et al. reported 1-, 3-, and 5-year tumor-free survival rates for salvage liver transplantation at $68.4 \%, 57.9 \%$, and $57.9 \%$ in patients who developed recurrent $\mathrm{HCC}$ within the Milan criteria after undergoing curative treatment. ${ }^{19}$ However, massive, multiple, and/or extrahepatic recurrence of $\mathrm{HCC}$ with or without major vascular invasion is associated with grave prognosis since curative treatment can no longer be applied in this setting. Furthermore, clinical outcome is more dreadful if this incident occurs early. Hence, we evaluated incidence, clinical significance, and predictive factors of recurrence beyond Milan criteria (widely accepted criteria for successful application of curative treatment) within 2 years (generally acknowledged point for definition of 'early' recurrence). ${ }^{2-4,18}$

In this study, 1-, 3-, and 5-year cumulative rates of recurrence were $23.1 \%, 58.4 \%$, and $70.8 \%$, respectively. It is comparable to previous long-term studies reporting intrahepatic distant recurrences at $24.4-25.6 \%, 59.5-63.3 \%$, and $73.1-74.8 \%$, respectively. ${ }^{6,7}$ One-, 3-, and 5-year initial recurrence rates beyond Milan criteria in our patients were $3.9 \%, 12.9 \%$, and $17 \%$, respectively. Lee, et al. reported early diffuse recurrence in $15.8 \%$ and Kotoh, et al. presented rapid and scattered recurrence in $8.0 \%$ after RFA. ${ }^{11,15}$ Tsuchiya, et al. reported cumulative rates of recurrence exceeding Milan criteria at $1-, 3$-, and 5 -years to be $15.1 \%$, $46.0 \%$, and $61.1 \%$, respectively in HCC patients treated with RFA. ${ }^{20}$ The lower rates of recurrence in our study may be due to 
the difference in the inclusion criteria for the RFA since our study enrolled patients with single small HCC, while Tsuchiya, et al. ${ }^{20}$ included patients within Milan criteria. In our study, early massive recurrence was noted in 27 patients (8.0\%) with the following reasons: detection of tumor(s) with size and/or numbers beyond Milan criteria ( $n=11,2.5 \%)$, vascular invasion $(n=3,0.7 \%)$, and extrahepatic metastasis ( $n=13,2.9 \%)$.

In this study, 1-, 3-, and 5-year cumulative rates of overall survival were $98.1 \%, 86.3 \%$, and $72.8 \%$, respectively. It was comparable to those of previous reports at 95.5\%-96.6\%, 77.9$80.5 \%$, and $59.7-60.2 \%$, respectively. ${ }^{6,7}$ This study shows that independent risk factors predictive of poor overall survival were older age, Child-Pugh Class B or C, and early massive recurrence. Our results are comparable to those of other previous studies on outcome after RFA. Age, Child-Pugh score, and serum AFP levels were suggested as prognostic factors for survival in a previous large-scale study from our institution. ${ }^{21} \mathrm{~A}$ Japanese prospective study comparing outcome after RFA and surgery described above showed that procedure type (surgery), AFP level, Child-Pugh class were negative factors associated with recurrence. ${ }^{22}$ Early massive recurrence resulted in 1-, 3-, and 5-year overall survival of $92.6 \%, 54.2 \%$, and $19.4 \%$, respectively, although initial tumor size was small with complete ablation. Tsuchiya, et al. also reported a significantly lower overall survival in patients with tumor recurrence beyond Milan criteria within one year. ${ }^{20}$

In our study, multivariable analysis identified initial tumor size $\geq 2 \mathrm{~cm}$ and tumor adjacent to the colon as the independent risk factors predictive of early massive recurrence. Early massive recurrence was as high as $45.5 \%$ in tumor size $\geq 2 \mathrm{~cm}$ and adjacent to colon, compared to $3.6 \%$ in patients with no risk factors. Kim, et al. analyzed 300 patients with $\mathrm{HCC}<4 \mathrm{~cm}$ treated with RFA and stated that tumor size $\geq 2 \mathrm{~cm}$ was associated with greater risk of recurrence. ${ }^{23}$ Lee, et al. also reported greater tumor size as the risk factor for recurrence after RFA. ${ }^{11}$ Histopathologically, HCC $<2$ $\mathrm{cm}$ have been reported to have greater areas of well-differentiated carcinoma with microsatellite lesions in about $3 \%$ of the cases which are usually within $5 \mathrm{~mm}$ of the tumor. ${ }^{24}$ However, in HCC $<3 \mathrm{~cm}$, microsatellite lesions confirmed after resection increased up to $19 \% .^{25}$ Difference in composition of tumor and increase in number of satellite lesions contribute to increase in massive recurrence rate after RFA. Although MRI was done in most of our patients for more accurate detection intrahepatic lesions before RFA, failure to detect minute lesions would be unavoidable due to limitation of current imaging modalities in these mostly cirrhotic patients. Presence of hidden lesions can lead to early and/or massive recurrence after RFA, especially in patents with relatively large tumors. ${ }^{26,27}$ In addition, insufficient work up for extrahepatic metastasis at the time of initial diagnosis can lead to early extrahepatic recurrence in our patients. ${ }^{28}$ In our study, tumor located within 1 $\mathrm{cm}$ of the colon was another risk factor for early massive recurrence. The topographical location of the tumor is an important factor to consider as RFA most commonly uses ultrasound (US) for guidance to localize the tumor. Any interference to obtaining a clear image (e.g. poor acoustic window) and a proper pathway to the tumor may hinder complete ablation of the tumor, which may lead to early massive recurrence. Although artificial ascites was made to separate the tumors and adjacent colon if applicable at our institution, sufficient thermal energy might not be delivered due to fear of collateral thermal injury in some cases. ${ }^{29}$ Consequent insufficient ablation seems to be associated with poor outcomes in these patients. Among 19 patients with tumor adjacent to colon in our study, artificial ascites was used for in 14 patients.

Proximity to any organ or surface of the liver in patients undergoing RFA was reported to be associated with high risk of insufficient margin and dissemination of malignant tumor cells from increased intratumoral pressure leading to early massive recurrence. ${ }^{23,30,31}$ While large tumor size (or advanced tumor stage) and proximity to major vessel or adjacent organ were commonly reported risk factors for early diffuse or scattered recurrence in previous studies and ours, high levels of tumor markers, poorly defined margin, poor pathologic differentiation, or presence of HCV infection were also suggested by some authors. ${ }^{11-14,20,23}$ Diverse inclusion criteria and RFA techniques as well as variable study design according to the authors may lead to the difference in risk factors among studies.

Our finding is limited by the retrospective nature of our study design. Decision to undergo RFA in each patient was at the discretion of the corresponding physicians, which may have led to developing a possible bias of our results. Despite the above limitation, this is the first study showing that early massive recurrence is not rare and one of the independent factors predictive of poor survival after RFA even in patients with single HCC. In addition, we revealed that tumor size $\geq 2 \mathrm{~cm}$ and proximity to colon were associated with high chance of early massive recurrence. Other treatment modalities including surgical resection can be suggested as better treatment option for HCC with such risk factors predictive of early massive recurrence.

In conclusion, early massive recurrence after RFA is a clinically significant, not-so-rare problem leading to poor overall survival in patients with single small HCC. In addition, tumor size $\geq 2 \mathrm{~cm}$ in 
size and proximity to colon of tumor were associated with high risk of early massive recurrence. For these high-risk group, application of treatment modality other than RFA could be considered, especially if infusion of artificial ascites between the tumor and adjacent colon is not successful enough.

\section{Conflicts of Interest}

The authors have no conflicts to disclose.

\section{REFERENCES}

1. Kim YS, Lim HK, Rhim H, Lee MW. Ablation of hepatocellular carcinoma. Best Pract Res Clin Gastroenterol 2014;28:897-908.

2. European Association For The Study Of The Liver, European Organisation For Research And Treatment Of Cancer. EASL-EORTC clinical practice guidelines: management of hepatocellular carcinoma. J Hepatol 2012;56:908-943.

3. Bruix J, Sherman M; American Association for the Study of Liver Diseases. Management of hepatocellular carcinoma: an update. Hepatology 2011;53:1020-1022.

4. Korean Liver Cancer Study Group, National Cancer Center. [Practice guidelines for management of hepatocellular carcinoma 2009]. Korean J Hepatol 2009;15:391-423.

5. Yu SJ. A concise review of updated guidelines regarding the management of hepatocellular carcinoma around the world: 2010-2016. Clin Mol Hepatol 2016;22:7-17.

6. Kim YS, Lim HK, Rhim H, Lee MW, Choi D, Lee WJ, et al. Ten-year outcomes of percutaneous radiofrequency ablation as first-line therapy of early hepatocellular carcinoma: analysis of prognostic factors. J Hepatol 2013;58:89-97.

7. Shiina S, Tateishi $R$, Arano T, Uchino $K$, Enooku $K$, Nakagawa $H$, et al. Radiofrequency ablation for hepatocellular carcinoma: 10-year outcome and prognostic factors. Am J Gastroenterol 2012;107:569577.

8. Sotiropoulos GC, Malago M, Molmenti EP, Radtke A, Brokalaki El, Nadalin $S$, et al. Disease course after liver transplantation for hepatocellular carcinoma in patients with complete tumor necrosis in liver explants after performance of bridging treatments. Eur J Med Res 2005; 10:539-542.

9. Imai K, Beppu T, Chikamoto A, Mima K, Okabe H, Hayashi H, et al. Salvage treatment for local recurrence of hepatocellular carcinoma after local ablation therapy. Hepatol Res 2014;44:E335-345.

10. Rossi S, Ravetta V, Rosa L, Ghittoni G, Viera FT, Garbagnati F, et al. Repeated radiofrequency ablation for management of patients with cirrhosis with small hepatocellular carcinomas: a long-term cohort study. Hepatology 2011;53:136-147.

11. Lee HY, Rhim H, Lee MW, Kim YS, Choi D, Park MJ, et al. Early diffuse recurrence of hepatocellular carcinoma after percutaneous radiofrequency ablation: analysis of risk factors. Eur Radiol 2013:23:190-197.

12. Yu HC, Cheng JS, Lai KH, Lin CP, Lo GH, Lin CK, et al. Factors for early tumor recurrence of single small hepatocellular carcinoma after percutaneous radiofrequency ablation therapy. World J Gastroenterol 2005;11:1439-1444.

13. Ruzzenente A, Manzoni GD, Molfetta M, Pachera S, Genco B, Donataccio $M$, et al. Rapid progression of hepatocellular carcinoma after Radiofrequency Ablation. World J Gastroenterol 2004;10:11371140.

14. Izumi N, Asahina Y, Noguchi O, Uchihara M, Kanazawa N, Itakura J, et al. Risk factors for distant recurrence of hepatocellular carcinoma in the liver after complete coagulation by microwave or radiofrequency ablation. Cancer 2001;91:949-956.

15. Kotoh K, Enjoji M, Arimura E, Morizono S, Kohjima M, Sakai H, et al. Scattered and rapid intrahepatic recurrences after radio frequency ablation for hepatocellular carcinoma. World J Gastroenterol 2005;11:6828-6832.

16. Poon RT, Fan ST, Ng IO, Lo CM, Liu CL, Wong J. Different risk factors and prognosis for early and late intrahepatic recurrence after resection of hepatocellular carcinoma. Cancer 2000;89:500-507.

17. Kang TW, Rhim H, Lee J, Song KD, Lee MW, Kim YS, et al. Magnetic resonance imaging with gadoxetic acid for local tumour progression after radiofrequency ablation in patients with hepatocellular carcinoma. Eur Radiol 2016;26:3437-3446.

18. Wu JC, Huang YH, Chau GY, Su CW, Lai CR, Lee PC, et al. Risk factors for early and late recurrence in hepatitis B-related hepatocellular carcinoma. J Hepatol 2009;51:890-897.

19. Chan AC, Chan SC, Chok KS, Cheung TT, Chiu DW, Poon RT, et al. Treatment strategy for recurrent hepatocellular carcinoma: salvage transplantation, repeated resection, or radiofrequency ablation? Liver Transpl 2013;19:411-419.

20. Tsuchiya K, Asahina Y, Tamaki N, Yasui Y, Hosokawa T, Ueda K, et al. Risk factors for exceeding the Milan criteria after successful radiofrequency ablation in patients with early-stage hepatocellular carcinoma. Liver Transpl 2014;20:291-297.

21. Choi D, Lim HK, Rhim H, Kim YS, Lee WJ, Paik SW, et al. Percutaneous radiofrequency ablation for early-stage hepatocellular carcinoma as a first-line treatment: long-term results and prognostic factors in a large single-institution series. Eur Radiol 2007;17:684692.

22. Hasegawa K, Makuuchi M, Takayama T, Kokudo N, Arii S, Okazaki M, et al. Surgical resection vs. percutaneous ablation for hepatocellular carcinoma: a preliminary report of the Japanese nationwide survey. J Hepatol 2008;49:589-594.

23. Kim JS, Kim W, So YH, Yu SJ, Kim BG. Topographical impact of hepatitis B-related hepatocellular carcinoma on local recurrence after 
radiofrequency ablation. J Clin Gastroenterol 2014;48:66-72.

24. Livraghi T. Single HCC smaller than $2 \mathrm{~cm}$ : surgery or ablation: interventional oncologist's perspective. J Hepatobiliary Pancreat Sci 2010;17:425-429.

25. Okusaka T, Okada S, Ueno H, Ikeda M, Shimada K, Yamamoto J, et al. Satellite lesions in patients with small hepatocellular carcinoma with reference to clinicopathologic features. Cancer 2002;95:19311937.

26. Inoue $T$, Kudo $M$, Komuta $M$, Hayaishi $S$, Ueda $T$, Takita $M$, et al. Assessment of Gd-EOB-DTPA-enhanced MRI for HCC and dysplastic nodules and comparison of detection sensitivity versus MDCT. J Gastroenterol 2012;47:1036-1047.

27. Rimola J, Forner A, Tremosini S, Reig M, Vilana R, Bianchi $L$, et al. Non-invasive diagnosis of hepatocellular carcinoma $\leq 2 \mathrm{~cm}$ in cirrhosis. Diagnostic accuracy assessing fat, capsule and signal intensity at dynamic MRI. J Hepatol 2012;56:1317-1323.
28. Seo HJ, Choi YJ, Kim HJ, Jeong YH, Cho A, Lee JH, et al. Evaluation of Bone Metastasis from Hepatocellular Carcinoma Using (18)F-FDG PET/CT and (99m)TC-HDP Bone Scintigraphy: Characteristics of Soft Tissue Formation. Nucl Med Mol Imaging 2011;45:203-211.

29. Kang TW, Lee MW, Hye MJ, Song KD, Lim S, Rhim H, et al. Percutaneous radiofrequency ablation of hepatic tumours: factors affecting technical failure of artificial ascites formation using an angiosheath. Clin Radiol 2014;69:1249-1258.

30. Mori Y, Tamai H, Shingaki N, Moribata K, Shiraki T, Deguchi H, et al. Diffuse intrahepatic recurrence after percutaneous radiofrequency ablation for solitary and small hepatocellular carcinoma. Hepatol Int 2009;3:509-515.

31. Rhim H, Goldberg SN, Dodd GD 3rd, Solbiati L, Lim HK, Tonolini M, et al. Essential techniques for successful radio-frequency thermal ablation of malignant hepatic tumors. Radiographics 2001;21(Suppl 1):S17-S35. 